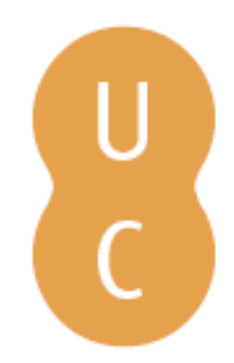

\title{
nommalina
}

\section{Uma pequena Roma no Norte da África uma análise de Leptis Magna}

Autor(es): $\quad$ Gonçalves, Ana Teresa Marques

Publicado por: Centro de Estudos Clássicos e Humanísticos; Imprensa da Universidade

URL

persistente: URI:http://hdl.handle.net/10316.2/31518

DOI: $\quad$ DOI:http://dx.doi.org/10.14195/978-989-8281-20-3_6

Accessed : $\quad$ 26-Apr-2023 11:16:46

A navegação consulta e descarregamento dos títulos inseridos nas Bibliotecas Digitais UC Digitalis, UC Pombalina e UC Impactum, pressupõem a aceitação plena e sem reservas dos Termos e Condições de Uso destas Bibliotecas Digitais, disponíveis em https://digitalis.uc.pt/pt-pt/termos.

Conforme exposto nos referidos Termos e Condições de Uso, o descarregamento de títulos de acesso restrito requer uma licença válida de autorização devendo o utilizador aceder ao(s) documento(s) a partir de um endereço de IP da instituição detentora da supramencionada licença.

Ao utilizador é apenas permitido o descarregamento para uso pessoal, pelo que o emprego do(s) título(s) descarregado(s) para outro fim, designadamente comercial, carece de autorização do respetivo autor ou editor da obra.

Na medida em que todas as obras da UC Digitalis se encontram protegidas pelo Código do Direito de Autor e Direitos Conexos e demais legislação aplicável, toda a cópia, parcial ou total, deste documento, nos casos em que é legalmente admitida, deverá conter ou fazer-se acompanhar por este aviso.

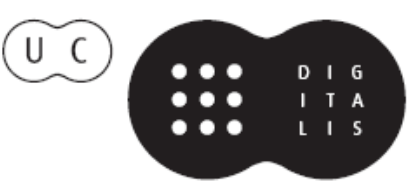




\section{Representações da Cidade Antiga}

categorias históricas e discursos filosóficos

\section{Gabriele Cornelli (Org.)}




\section{UMA PEQUENA RoMA No NorTE DA ÁFrica UMA ANÁLISE DE LEPTIS MAgNa}

A Little Roma in the North Africa: an Analysis of Leptis Magna

Ana Teresa Marques Gonçalves ${ }^{1}$

Resumo: $\mathrm{O}$ objetivo deste artigo é analisar as várias construções feitas na cidade de Leptis Magna, principalmente a partir do governo de Otávio Augusto, com o intuito de transformá-la numa pequena Roma no norte da Africa.

Palavras-chave: Roma, Leptis Magna, Império, África, Cidades.

Abstract: The objective of this paper is to analyse several constructions in the Leptis Magna, after the Octavius Augustus Government in the Roman Empire, for transformed this city in the little Rome in north of África.

Keywords: Rome, Leptis Magna, Empire, Africa, Cities.

Muito se tem discutido a respeito do conceito de "romanização" e sobre a relação que Roma manteve com suas províncias, ao longo do Império Romano. Em um texto intitulado Art as Resistance and Negotiation, Jane Webster defende que a arte provincial foi tanto expressão de dominação quanto de resistência. Para Webster, os contextos interculturais permitiram a produção de edificações nas quais se perceberia muito mais a negociação de modelos e características estéticas do que processos que poderiam ser denominados de "dominação", “emulação" ou "aculturação" (Webster, 2003: 24).

Ao analisarmos as construções provinciais, devemos ficar atentos aos materiais usados, aos interesses envolvidos, às técnicas empregadas, à localização espacial da obra, bem como à releitura que os patronos e artesãos provinciais faziam dos cânones imperiais a partir da destreza que possuíam.

Ovídio, na obra Os Fastos, comenta que "o mundo e a cidade de Roma ocupam o mesmo espaço” (Ov. Os Fastos. 2.684). Ser cidadão de Roma era se ver como cidadão do mundo conhecido, pois a própria ocupação do espaço partia do modelo edificante construído tendo por base a disposição territorial romana. Nas palavras de Catherine Edwards e Greg Woolf, Roma foi se tornando uma cosmópole, num longo processo temporal, com a cidade sendo constantemente reconstruída (Edwards; Woolf, 2004: 8), por meio de múltiplas intervenções no espaço construído.

Paul Zanker, num livro dedicado à cidade de Pompéia, define que o espaço urbano é antes de tudo um reflexo da sociedade que o construiu e que lhe dá sentido de ocupação, definição de zonas privadas e públicas e características de identificação. Qualquer análise a respeito de uma cidade deve partir das conexões

${ }^{1}$ Professora Adjunta de História Antiga e Medieval da Universidade Federal de Goiás (UFG). Doutora em História Econômica pela Universidade de São Paulo (USP). 
que se estabelecem entre o uso do espaço e as vidas, hábitos e necessidades de seus residentes. Uma cidade é, primeiramente, uma combinação de espaços públicos com espaços privados. Em ambos, podemos identificar a união da religião com a política, para celebrar a unidade, a ordenação e a soberania de Roma. Enquanto as construções particulares servem como indicadores de status social e identitário, as construções públicas demonstram honras publicizadas por meio da publica magnificentia (Zanker, 1998: 1-25). Interessa aos membros das elites provinciais divulgar, por meio das edificações, sua lealdade ao poder central, esperando assim manter benefícios já obtidos ou conseguir novas benesses.

Mas, como nos lembra Marc Augé, no seu livro Não-Lugares, um lugar pode ser definido como identitário, relacional e histórico, mas o que transforma um lugar em um espaço é a ação dos passantes, que, ao se relacionarem com o lugar, transformam-no em um "lugar praticado", em um "cruzamento de forças motrizes”, enfim, em um “espaço" (Augé, 1994: 73-75).

Segundo Simon J. Keay, as cidades romanas espalhadas por todo território inserido no limes são centros econômicos e símbolos culturais. As cidades se desenvolviam pela virtude de seu comportamento cultural e eram sustentadas pelas virtudes de regras legais, que definiam os direitos e deveres de seus habitantes. As cidades auxiliavam na disseminação da ideologia imperial e do culto necessário para manutenção da coesão do Império. A coleta de taxas e impostos e a administração da justiça incluíam as comunidades na unidade política romana. Por maiores que fossem as diferenças regionais e culturais, as cidades eram organizadas num sistema administrativo, político, econômico e religioso que as separava em, municipia, coloniae e civitates, de acordo com seu tamanho, sua importância estratégica, econômica e política, bem como sua relação com o centro do poder (Keay, 1994: 253-254).

De acordo com Salústio, na História da Guerra Jugurtina, a cidade de Lepcis foi fundada por pessoas vindas de Tyro, na Fenícia, que, fugindo de uma guerra civil, procuraram se estabelecer próximo a dois golfos marítimos, os quais permitiam um contato tranqüilo com o mar Mediterrâneo e uma brisa constante que transformava o território numa agradável região. Essas pessoas teriam se estabelecido primeiramente em um promontório, uma leve elevação do terreno, que lhes permitia observar os campos em volta, garantindo-lhes, assim, uma situação de defesa no caso de um ataque, além de mantê-los próximos ao mar. Eles entraram em contato com os habitantes da Numídia, seus vizinhos, e com eles desenvolveram relações de comércio e de amizade (Salústio. História da Guerra Jugurtina. 1.26).

Os arqueólogos que começaram a escavar a cidade no final do século XIX chamaram essas primeiras modestas construções de "Lepcis Púnica", pela influência fenícia e cartaginesa inicial. Lepcis começou a mudar a partir do governo de Otávio, ao se tornar um dos mais importantes portos que ligavam o norte da África à Península Itálica (Di Vita-Evrard, 1998: 50-51). Além disso, o território de Lepcis e seu porto foram fundamentais na conquista da Numídia, convertendo-se em ponta de lança do ataque romano. Seu porto recebia não apenas navios de comércio, mas também a esquadra bélica romana. 
Paul Zanker, no livro Augusto y el Poder de las Imágenes, enfatiza que no governo de Otávio se criou uma nova linguagem iconográfica que se espalhou por todo o Império. Interessava às elites provinciais citadinas proclamarem em mármore sua adesão ao vencedor das guerras civis. Os teatros e os edifícios dedicados ao culto do genius do imperador - sua possibilidade de bem agir em prol da comunidade - foram erigidos em honra de Roma e de seu governante (Zanker, 2004: 343, 372). Ginette Di Vita-Evrard, ao se referir a Lepcis durante os governos de Otávio e Tibério, denomina-a de "a cidade da pedra branca" (Di Vita-Evrard, 1998: 54), referindo-se ao mármore alvo que passou a cobrir as novas construções, edificadas para comemorar o novo momento político imperial. Momento este cuja resolução final tinha se dado a partir das costas africanas, numa batalha naval travada em Actium, em 31 a.C., em que Marco Antônio e Cleópatra contrapunham sua esquadra à frota comandada por Otávio e seus aliados.

Nesse final do I século a.C., um grande mercado foi erigido em Lepcis, que tinha por função servir de ponto de encontro para os citadinos, abrigar pequenas tendas de comércio e estabelecimentos de venda de comidas e bebidas, além de servir como local de armazenamento de materiais que chegavam ou saíam pelo porto. Sua inscrição dedicatória, feita em latim e púnico, nos informa que ele ficou pronto em 8 a.C. e foi feito sob patrocínio do rico Annobal Tapapius Rufus, flamem imperial, que no próprio nome indica a miscelânea da cultura púnica com a latina no espaço de Lepcis. $\mathrm{O}$ acesso ao mercado, a partir do porto, foi garantido pela construção de uma longa via reta, margeada de colunas de mármore, denominada de Via Triunfal. Nessas colunas foram gravadas imagens de caduceus, que integram os atributos de Mercúrio, divindade vinculada aos comerciantes e viajantes, e também ligada ao simbolismo mágico púnico.

Durante o governo de Tibério, esse mercado foi ampliado, devido ao incremento das atividades portuárias. O responsável pela ampliação, indica-nos a epigrafia, foi o rico Marcus Heliodorius Apollonides, que na inscrição dedicatória se diz amicus do Imperador Tibério. Como define David Konstan, embora o conceito de amizade não seja uniforme nas várias culturas, ou dentro de uma única cultura com o passar do tempo, a essência da relação do que os romanos denominaram de amicitia era a criação de um vínculo mutuamente íntimo, leal e amoroso, que não se origina da associação a um grupo normalmente marcado pela solidariedade nativa, como família ou tribo. A amizade é uma relação adquirida e não uma relação atribuída, uma relação conquistada que podia ser mantida pela troca de correspondência ou pela visita mútua (Konstan, 2005: 1). Ao se propalar amigo do imperador, o patrocinador da obra elevava o seu status frente a todos os citadinos e demonstrava sua proximidade do poder imperial, mesmo residindo numa comunidade disposta tão longe de Roma.

Nesse mesmo período, foi construído um arco em homenagem a Tibério e um teatro semicircular, aproveitando-se uma elevação natural do terreno. O arco foi disposto no meio do mercado, entre dois prédios circulares, um usado para a venda de legumes, frutas e verduras, e, o outro, para o comércio da carne. 
Portanto, num local de grande movimento de pessoas. $\mathrm{O}$ arco foi dedicado por toda a cidade, comemorando a pavimentação das ruas em 35-36 d.C. O teatro teve sua construção patrocinada por Annobal Himilchonis, filho de Tapapius Rufus, segundo sua inscrição dedicatória (tabula ansata), indicando a permanência dessa família entre as mais poderosas e ricas da cidade. Em suas galerias foram encontrados vários pedestais de estátuas, dedicadas aos imperadores e às divindades, como Ceres, Líber Pater (leitura norte-africana de Dioniso) e Tyché (Fortuna ou Boa Sorte).

Dessa época, temos a construção de três grandes templos dedicados aos deuses protetores da cidade: Ceres, edificado próximo ao teatro; Shadrapa-Líber Pater e Milkastart-Hércules, construído perto do mercado; e Apolo, divindade cujo culto foi bastante amplificado por Augusto. Em frente a esse templo, foram dispostas quatro estátuas, que hoje se encontram no museu de Trípoli, dedicadas a Augusto, Roma, Tibério e Lívia. Em 12 d.C., construiu-se um chalcidicum, isto é, um vestíbulo quadrado, cercado de colunas, onde, no centro, encontrava-se uma estátua de Augusto e um altar (ara) dedicado ao culto ao numen do Imperador. Pela inscrição, sabemos que foi erigido por ordem de Iddibal Caphada Aemilius, em honra do poder divino do governante.

No governo de Nero, houve a construção de dois templos. Um dedicado a Roma e ao Divino Augusto, e outro dedicado a Júpiter, à Juno e à Minerva. É de seu governo também a construção de um Anfiteatro capaz de receber 16 mil expectadores, já demonstrando o aumento populacional da cidade e sua capacidade de atrair populações vizinhas para os jogos a serem ali realizados. Pelos afrescos encontrados no interior do próprio anfiteatro e nas casas da cidade, havia certa predileção pelas venationes, ou seja, pelos combates travados entre homens e feras. Devemos, assim, separar os munera das venationes. Os munera eram combates efetivados entre homens, relembrando batalhas do passado ou fazendo parelhas de combatentes de acordo com seus armamentos, enquanto as venationes eram lutas entre animais ou verdadeiras caçadas, representadas na arena dos anfiteatros, que contrapunham homens a animais. Com as conquistas romanas de novas províncias, animais cada vez mais exóticos vinham para os anfiteatros tanto de Roma quanto das províncias, e sua presença nos jogos servia exatamente para relembrar ao público a força e a extensão do domínio romano. Eram elefantes, rinocerontes, leões, girafas, hienas e também animais menores, como cães e gatos (Kyle, 2007: 297-298).

Do governo de Nero, também datam as construções do circus, para a realização de corridas de cavalos e carros (bigas e quadrigas), e um grande altar dedicado a Nemesis, deusa patrona dos jogos (os ludi).

No período de Vespasiano, Lepcis recebeu a construção de um pequeno templo dedicado a Cibele, deusa mãe oriental, que, como Ceres, vinculava-se aos cultos agrários. Essa divindade recebeu muito apoio durante os governos dos Flávios. Realizar a construção de um templo dedicado a uma divindade apoiada pela família imperial era uma forma astuciosa de proclamar a lealdade a Roma. Nesse período, Lepcis foi elevada à categoria de municipium e, em 77-78 d.C., fez-se um arco em honra a Vespasiano, patrocinado por Tiberius 
Claudius Sestius, que também foi responsável por pagar a construção de um altar dedicado ao divino Augusto e pela remodelação da orquestra do teatro.

Trajano enfrentou várias revoltas na Numídia e usou Lepcis como centro estratégico de defesa da soberania romana na região. Passou-se então, a partir de 110 d.C., a chamá-la de Colonia Ulpia Traiana Augusta Fidelis Lepcis Magna, ressaltando-se a fidelidade de Lepcis para com Roma pelo epíteto fidelis agregado ao seu nome. De seu governo data também a construção da Basílica Ulpia, cujo nome já indica a atribuição da justiça em última instância ao próprio Imperador, que se fazia presente por meio das leis a serem seguidas e dos pretores peregrinos, responsáveis por levar a lei e a ordem romana às províncias. Construiu-se ainda uma bela cúria, na qual passaram a se reunir os membros do senado local, os decuriões. Para comemorar as benesses econômicas e políticas garantidas pela concessão do status de colônia, foi construído, às expensas públicas, com gerenciamento dos decuriões, o primeiro arco quadrifronte da comunidade, próximo ao mercado, dedicado a Trajano e suas vitórias militares.

No período de Adriano, Lepcis verificou a construção de suas maiores Termas. Inicialmente foi construído um extenso aqueduto, com mais de vinte quilômetros, em 120 d.C. A seguir, ao longo do aqueduto, foram erigidas várias fontes para que a população tivesse acesso à água abundante. As termas só ficaram completamente prontas em 137 d.C., sendo inauguradas já no governo de Antonino Pio. Quem aparece na inscrição dedicatória oferecendo a obra a Adriano e ao povo de Lepcis é Quintus Servilius Candidus, que, por casamento, fazia parte da família de Tiberius Claudius Sestius, cujos membros acabaram chegando ao Senado de Roma no III século, durante o governo dos Severos.

As termas contavam com salas para caldarium, frigidarium e tepidarium, uma grande piscina ao ar livre (natatio), latrinas públicas, quartos para a troca de roupa e massagens com óleos aromáticos, palaestra para a prática de esportes e treino de lutas, uma êxedra e uma grande fonte de água. Em todas as salas e ao redor da piscina, foram encontrados suportes para estátuas também dedicadas aos imperadores e às divindades, como uma grande estátua de Marte (Di Vita-Evrard, 1998: 92).

Em torno do II século a.C., tinham aparecido em Roma, capital do Império e espaço de divulgação dos cânones de construção, os primeiros banhos públicos (balnea), que se multiplicaram devido à modesta taxa de ingresso (balneaticum). A sucessão dos ambientes obedecia à regra, quase canônica, do ciclo hidroterápico: primeiro a prática de alguns exercícios físicos na palaestra, a seguir vinha o banho quente (caldarium), depois as saunas (sudatio), as piscinas de águas mornas (tepidarium) e a piscina de água fria (frigidarium). Aos poucos, as salas de banhos foram aumentando de tamanho e as chamadas Thermae ganharam áreas recreativas e culturais (lojas, bibliotecas, salas de reunião, solários, galerias, entre outros espaços).

As primeiras grandes termas foram construídas em Roma por Agripa em 33 a.C., com capacidade para receber cerca de 170 pessoas por dia. Tornara-se tradição que os governantes erigissem termas para agradar a população de Roma. Por exemplo, só para citar algumas, Nero construiu as suas termas em 
62 d.C. (Thermae Neronianae); Tito em 80 d.C. (Thermae Titianae); Trajano em 110 d.C. (Thermae Traianae) (Lombardi; Corazza, 1995: 15-16). Membros de todas as dinastias preocuparam-se em construir esses verdadeiros complexos recreativos, nos quais as termas tinham se transformado. $\mathrm{E}$ esse exemplo, vinculado também à saúde e ao bem estar dos citadinos, espalhou-se pelas cidades provinciais.

As termas foram terminadas contando com o patrocínio de Tiberius Plautinus Lupus e Marcius Rusonianus, membros de famílias poderosas desde o governo de Cláudio. Foi a construção mais cara até então, e contava com grande quantidade de mármore e estátuas dedicadas a Antínoo, jovem bitínio favorito de Adriano, e ao atleta Diadumeno, sendo esta uma cópia de uma estátua grega de Policleto. Tais estátuas integram atualmente os acervos dos museus de Trípoli e Leptis na Líbia.

No segundo século também foi erguido um arco em honra de Antonino Pio, do qual sobraram apenas os frisos decorados com cabeças de medusas, górgonas e vitórias aladas. Durante seu governo, sabemos que foi construído em Lepcis um templo dedicado a Serapis. E duas famílias se uniram para angariar 500 mil sestércios e reconstruir o teatro, cobrindo-o de mármore e colocando estátuas de Castor e Pólux na entrada. Em 174 d.C. foi consagrado um arco a Marco Aurélio, a quem também foi dedicada a reconstrução do circus, o qual recebeu cobertura de mármore e mais estátuas, obras estas patrocinadas por Marcus Iunius Crescens. Essas reconstruções buscavam demonstrar o enriquecimento e crescimento da colônia e o fortalecimento político de sua aristocracia.

Porém, como afirma Procópio de Cesaréia, na obra História das Guerras, Lepcis se transforma num "sonho do Imperador" (Procópio. História das Guerras. 2.3), durante os governos de Septímio Severo e de seu filho e herdeiro Caracala. Como Lúcio Septímio Severo havia nascido em Lepcis, ele quis honrar sua cidade. Ele concedeu, por volta de 202/203 d.C., o ius italicum (Ward-Perkins, 1948: 59), tendo Lepcis sido elevada à categoria de colonia juris italici (Caffarelli, 1963: 69), que garantia aos seus habitantes direitos e deveres iguais aos dos habitantes da Península Itálica. Com isso, em todos os monumentos severianos a grafia do nome da cidade mudou. De Lepcis, com "c", lembrando a grafia púnica, para Leptis com " $\mathrm{t}$ ", mais próxima de uma grafia latina. Como havia outra Leptis na costa da Tunísia, passou-se a denominar esta de Leptis Minus (a menor - na atual Tunísia) e a pátria de Septímio de Leptis Magna (a maior - na atual Líbia). Em termos de tamanho e magnificência, Leptis só perdia para Cartago, capital da província da África.

Severo mandou ordens de Roma para que os aristocratas locais, muitos membros de sua própria família, construíssem um fórum novo, um templo dedicado à gens Septimia, uma nova basílica, um conjunto de tabernae e um nymphaeum, bem como promovessem, com dinheiro muitas vezes enviado da res privata do Imperador, a ampliação do porto, a restauração do importante farol da cidade e a ampliação da estrutura do circus (Ward-Perkins, 1948: 61). Mandou também reconstruir, usando vários tipos de mármore, as colunas da 
Via Triunfal, que passou a se chamar Via Colonata, sendo adornada com cenas que remetiam à Gigantomaquia - a luta dos gigantes e dos deuses gregos nma época em que Severo acabava de derrotar Dídio Juliano, Pescênio Nigro e Clódio Albino. Muitas destas obras começaram a ser construídas no governo de Septímio, mas só foram concluídas no período de Caracala, que nas inscrições dedicatórias mandou gravar essas informações, para enfatizar a continuidade de seu governo com relação ao governo de seu pai.

Acredita-se que o templo dedicado à gens Septimia deveria conter estátuas de Septímio, Júlia, Caracala e Geta, e de Liber Pater e Hércules (Caffarelli, 1963: 92-95), mas, infelizmente, dois grandes terremotos destruíram grande parte dessas construções. O primeiro ocorreu entre 306 e 310 d.C., e o segundo teria ocorrido em 21 de julho de 365 d.C., sendo a maioria de seus monumentos transformados ou abandonados (Di Vita, 1994: 163). O porto, especificamente, foi uma ampliação das construções anteriormente realizadas por Trajano (Bartoccini, 1962: 228-243).

Giacomo Guidi estudou especificamente a basílica construída por Severo e terminada por Caracala. Em seu interior, descobriu três inscrições, publicando a menos fragmentada, que se encontrava no interior do prédio e exemplifica bem a extensão das inscrições do período severiano, nas quais aparecem os vários títulos de Septímio, os vários epítetos de Caracala e toda a filiação antonina, remontando até Nerva. Por esta inscrição sabemos que a construção foi iniciada no governo de Septímio e terminada em 216 d.C. por Caracala (Guidi, 1929: 239). Os afrescos pintados nas paredes da basílica remetiam aos trabalhos de Hércules, que, como vimos, era uma das divindades protetoras de Leptis Magna.

Conhece-se a denominação de Forum Novum Severianum a partir de uma inscrição achada no interior desse local e que deveria ser de um pedestal de uma estátua de um nobre chamado Flávio Petásio, que foi patrono da cidade e recebeu a honra de colocar uma imagem sua neste novo local, por volta do IV século d.C. (CIL, VIII, n. 566). Deste fórum, faziam parte três templos; um dedicado a Hércules, outro a Liber Pater e um terceiro dedicado a Roma, ao divino Augusto e à família Severiana. $\mathrm{Na}$ frente deste último, que ficava entre os dois dedicados às divindades protetoras da cidade, construiu-se uma rostra, um palanque para os oradores. Na praça em frente aos templos ficava um nymphaeum, ornado com colunas e estátuas, de onde jorrava água. Infelizmente, não foram encontradas inscrições nem no nymphaeum nem na Via Colonata. Contudo, foram achadas algumas inscrições características de pedestais de estátuas em toda a extensão do Fórum, demonstrando que ele era adornado por estátuas de imperadores, magistrados e oficiais graduados e importantes para a vida citadina (Bartoccini, 1962: 240). De acordo com Michael Grant, o Fórum de Leptis Magna era um aperfeiçoamento do Fórum de Roma e visava a imitá-lo de forma melhorada (Grant, 1999: 85).

Segundo os estudos de Serena E. Vittozzi, o Fórum, dentro do qual se encontrava o templo dedicado à gens Septimia, tinha um programa decorativo que celebrava em si mesmo a divina domus, com a inclusão de máscaras 
gorgônicas e nereidas entre os arcos do Fórum. Vittozzi argumenta que as máscaras gorgônicas eram associadas a Alexandre Magno e representavam a providentia de Septímio e de Caracala, e que as nereidas significavam fertilidade e podiam ser associadas à Júlia Domna. Assim, as imagens de concórdia dentro da domus severiana e de poder dos imperadores já começavam nos arcos do Fórum que precediam o templo (Vittozzi, 1992: 719-751).

Antes disso, os Severos teriam recebido da cidade e de seus patronos um arco quadrifronte (quadrifrons) e uma exedra. P. Romanelli divulgou, em 1925, a inscrição encontrada nesta exedra. Ela está bastante fragmentada, mas indica que ela foi dedicada em 198 d.C. pelos procônsules da província da África para todos os quatro membros da família imperial, mas a menção a Geta foi apagada posteriormente (Romanelli, 1925: 128).

Para Daniela S. Corlàita, a seqüência de arcos construídos desde Tibério até Septímio em Leptis Magna indicaria a ampliação do território da cidade em direção ao sul, pois a população foi crescendo de 100 mil para $150 \mathrm{mil}$ habitantes ao longo do Principado (Corlàita, 1979: 49). A inscrição que deveria dedicar o Arco também se perdeu, mas a maioria dos historiadores e arqueólogos que estudaram seus relevos defende que foi erigido pela elite provincial para comemorar as vitórias do filho da cidade frente aos Partos, repercutindo nas províncias uma ação política também tomada pelo Senado de Roma, ao dedicar a Septímio e seus filhos o Arco do Fórum Romano. No Arco quadrifonte dedicado a Septímio e seus familiares, vemos relevos que ressaltam a união da família imperial, a imagem de Caracala como imperator destinatus, a ligação dos Severos com as divindades e a virtude militar severiana (Ghedini, 1982: 68).

Existem autores, como J. B. Ward-Perkins, A R. Birley e P. W. Towsend, que defendem que algumas dessas construções, inclusive o Arco quadrifronte, teriam sido feitas visando embelezar a cidade para a visita que Septímio teria feito a sua cidade natal, ao longo de uma viagem mais longa à África (Ward-Perkins, 1953: 227; Birley, 1971: 216-221; Townsend, 1938: 522). Todavia, há outros autores, como T. Kotula e F. Ghedini, que não acreditam que Septímio tenha realmente ido à África. Esses argumentam que nem Herodiano nem Dion Cássio nem a História Augusta narram essa viagem, que não há inscrições comprovando a viagem, mas apenas a intenção de ir à África, e que os monumentos teriam sido construídos apenas porque o Imperador teria divulgado que pretendia ir à África, mas que teria cancelado a viagem ao ter que retornar a Roma, exatamente para comemorar os decennalia de governo em 202 d.C. (Kotula, 1985: 151-165; Ghedini, 1982: 69-71). Kotula ainda enfatiza que existiram várias visitas imperiais que foram difundidas, com o intuito de inspecionar as províncias, mas que nunca foram realizadas. $\mathrm{E}$ a visita a Leptis Magna estaria entre elas (Kotula, 1985: 162).

$\mathrm{O}$ arco, revestido todo de mármore, foi erguido no encontro das duas principais avenidas de Leptis Magna (decumanus principal - a Via Oea/ Alexandria - com o cardo maximus - que era a via triunfal da cidade). Dele restaram alguns relevos que comemoram a vitória pártica, enfatizando a união 
familiar, que foi também o tema principal das construções severianas na cidade. Restaram-nos partes de quatro grandes painéis e um conjunto fragmentado de painéis menores. Num dos painéis, há a representação de um sacrifício de um touro, no qual apareceriam Septímio, Caracala, Júlia Domna, Geta, Plautiano e vários aristocratas e militares. Em outro, Septímio aparece sentado com os atributos de Júpiter, e Júlia Domna com os de Juno, tendo a imagem de um pavão próximo aos seus pés, ladeados por Minerva com uma coruja e pela Tyché da cidade de Leptis Magna. Num terceiro painel, há o que, inicialmente, foi visto como uma procissão triunfal (Ward-Perkins, 1951: 230) ou como o ingresso triunfal de Septímio em sua visita a Leptis Magna (Bartoccini, 1931: 62), mas que hoje é interpretado como a representação do retorno de Severo a Roma (o reditus) para as comemorações de seus decennalia, isto é, como a representação da Virtus Augusti em seu momento máximo e da Felicitas Temporum (Ghedini, 1982:70-73). No quarto painel, há a imagem da dextrarum iunctio, ou seja, o aperto de mãos realizado entre Septímio e Caracala, que foi feito Augusto durante as guerras contra a Pártia, sendo observados por Geta, aclamado César, tendo ao fundo a Tyché de Leptis Magna e o deus Liber Pater, uma das divindades protetoras da cidade.

Assim, em dois painéis vemos imagens divulgando a pietas religiosa dos Severos (Septímio e Júlia Domna como Júpiter e Juno, e o sacrifício do touro), em um, a concordia Augustorum (o aperto de mãos dado por Caracala e Septímio) e, em outro, a virtus militar em seu aspecto absoluto (a procissão do adventus de Severo em Roma) (Ghedini, 1982: 79).

Dentre os painéis menores, destacam-se a representação do cerco a uma cidade oriental, a captura de prisioneiros, a adlocutio, a presença de Hércules, um dos deuses protetores de Leptis Magna, de Marte e várias vitórias e troféus, que enfeitavam o Arco. Desse modo, nas imagens menores, percebe-se a continuidade da divulgação dos mesmos valores, atributos e representações que caracterizaram os relevos maiores que enfeitavam o arco, constituindo-se em suportes de mensagens políticas.

Sabemos que o mercado de Leptis foi reconstruído no governo de Constantino e que, durante a Tetrarquia, a cidade se transformou em capital da província da Tripolitânia, recebendo o palácio do governador romano e toda a administração provincial. O Fórum recebeu em 383 d.C. uma estátua do Imperador Arcádio e a basílica severiana foi transformada na Igreja da Mãe de Deus no governo de Justiniano (Di Vita-Evrard, 1998: 145). Portanto, vemos como ao longo de todo Alto Império, vários imperadores promoveram obras na cidade africana e receberam honras gravadas na pedra em troca da concessão de benefícios para a população da cidade como um todo ou para membros de sua aristocracia em particular. Leptis Magna foi se constituindo numa pequena Roma no norte da África, adaptando ao seu terreno e à destreza de seus artífices os cânones que chegavam da capital imperial, na busca de se fazer notar aos olhos dos poderosos. 


\section{Bibliografia}

Documentos Textuais:

Dio's Roman History. (1961) Trad. Earnest Cary. London: William Heinemann. (The Loeb Classical Library, v. 9)

Erodiano. (1967). Storia dell'Impero Romano dopo Marco Aurelio. Trad. Filippo Càssola. Firenze: Sansoni.

Herodiano. (1985). Historia del Imperio Romano después de Marco Aurélio. Trad. Juan J. Torres Esbarranch. Madrid: Gredos.

Hérodien. (1990). Histoire de l'Empire Romain après Marc-Aurèle. Trad. Denis Roques. Paris: Les Belles Lettres.

Ovídio. (1948). Os Fastos. Trad. Antônio Luís Seabra e Antônio Feliciano de Castilho. Rio de Janeiro: W. W. Jackson.

Cesaréia, Procópio de. (2000). Historia de las Guerras. Trad. Francisco Antonio Garcia Romero. Madrid: Gredos.

Salústio. Guerra Jugurtina. (1988). Trad. Barreto Feio. São Paulo: Tecnoprint.

The Scriptores Historiae Augustae. (1953). Trad. David Magie. London: William Heinemann. (The Loeb Classical Library, v. 1 e 2).

\section{Obras Gerais:}

Augé, M. (1994). Não-Lugares: introdução a uma Antropologia da supermodernidade. Campinas: Papirus.

Bartoccini, R. (1962). Il Porto di Leptis Magna nella sua Vita Economica e Sociale. In Hommages à Albert Grenier. Bruxelles: Latomus, 228-243.

Bartoccini, R. (1927). Guida di Lepcis. Roma: Arte Illustrata.

Bartoccini, R. (1931). L’Arco Quadrifronte dei Severi a Lepcis. Africa Italiana. Bérgamo, v. 4, n. 1-2, 32-152.

Birley, A. (1971). Septimius Severus: The African Emperor. London: Eyre and Spottiswoode.

Caffarelli, E. V. et al. (1963). Leptis Magna. Roma: Astoldi.

Corazza, A.; Lombardi, L. (1995). Le Terme di Caracalla. Roma: Fratelli Palombi.

Corlàita, D. S. (1979). La Situazione Urbanistica degli Archi Onorari nella Prima Età Imperiale. In Achille, M. G. ed. Studi sull'Arco Onorario Romano. Roma: L'Erma di Bretschneider, 29-80. 
Curtis, C. D. (1908). Roman Monumental Arches. In Supplementary Papers Of The American School Of Classical Studies In Rome. v. 2. London: Macmillan, 26-73.

Di Vita-Evrard, G. (1994). Leptis Magna. In Actas del XIV Congreso Internacional de Arqueología Clásica. Tarragona: Editora de la Universitá, 159-163.

Di Vita-Evrard, G. (1998). Lepcis. In Di Vita, A. et al. Libya: The Lost Cities of the Roman Empire. Cologne: Konemann, 44-145.

Edwards, C.; Woolf, G. (2004). Cosmopolis: Rome as World City. In Edwards, C.; Woolf, G. Rome: The Cosmopolis. Cambridge: University Press, 1-20

Ghedini, F. (1982). Il Panello Nord Ovest dell'Arco dei Severi a Leptis Magna: Una Proposta di Lettura. Rivista di Archeologia, Roma, v. 6, 68-79.

Grant, M. (1999). The Collapse and Recovery of the Roman Empire. London: Routledge.

Guidi, G. (1929). La data di costruzione della basilica di Leptis Magna. Africa Italiana. Bergamo, v. 2, n. 4, 231-245.

Johns, C. (2003). Art, Romanisation and Competence. In Scott, S.; Webster, J. eds. Roman Imperialism and Provincial Art. Cambridge: University Press, 9-23.

Keay, S. J. (1994). Towns in the Roman World: Economic Centers or Cultural Symbols? In Actas del XIV Congreso Internacional de Arqueología Clásica. Tarragona: Editora de la Universitá.

Konstan, D. (2005). A amizade no mundo clássico. São Paulo: Odysseus.

Kotula, T. (1986). Thèmes de la Propagande Impériale à travers les Inscriptions Africaines du Bas-Empire Romain. Bulletin Archéologique. Paris, v. 19, 257-263.

Kotula, T. (1990). Le Culte de la Gens Impériale: son Éclipse au IIIe. Siècle? In Croisille, J.M. (ed.). Neronia IV. Bruxelles: Latomus, 52-57.

Kotula,T.(1985). Septime Sévère, A-T-ilVisité l'Afrique en tant qu'Empereur? Eos. Gdansk, v. 73, 151-165.

Kyle, D. G. (2007). Sport and Spectacle in the Ancient World. Oxford: Blackwell.

Romanelli, P. (1959). Storia delle Province Romane dell'Africa. Roma: L'Erma di Bretschneider.

Romanelli, P. (1925). Leptis Magna. Roma: Arte Illustrata.

Sennett, R. (1997). Carne e Pedra. Rio de Janeiro: Record. 
Townsend, P. W. (1938). The Significance of the Arch of the Severi at Lepcis. American Journal of Archaeology. Boston, v. 42, n. 1, 512-524.

Vittozzi, S. E. (1992). Forum Novum Severianum di Leptis Magna: La Ricostruzione dell'Area Porticata e i Clipei com Protomi di Gorgoni e Nereidi. Atti del X Convegno di Studio su "L'Africa Romana". Sassari, v. 10, n. 2, 719-751.

Wallace-Hadrill,A. (1990). Roman Arches and Greek Honours: The Language of Power at Rome. Proceedings of the Cambridge Philological Society. Cambridge, v. 216, 143-173.

Ward-Perkins, J. B. (1981). Roman Imperial Architeture. New York: Penguin.

Ward-Perkins, J. B. (1951). The Art of the Severan Age in the Light of Tripolitanian Discoveries. Proceedings of the British Academy. London, v. 37, 269-304.

Ward-Perkins, J. B. (1952). Excavations in the Severan Basilica at Lepcis Magna. Papers of the British School at Rome. London, v. 20, 111-121.

Ward-Perkins, J. B. (1953). The Arch of Septimius Severus at Lepcis Magna. Archaeology. New York, v. 4, n. 4, 226-231.

Ward-Perkins, J. B. (1948). Severan Art and Architecture at Lepcis Magna. Journal of Roman Studies. v. 38. London, 59-80.

Webster, J. "Art as Resistance and Negotiation", in Scott, S.; Webster, J. eds. (2003) Roman Imperialism and Provincial Art. Cambridge: University Press.

Zanker, P. (2005). Augusto y el Poder de las Imágenes. Madrid: Alianza.

Zanker, P. (1998). Pompeii: Public and Private Life. Harvard: University Press. 